\title{
Article
}

\section{Combined Developmental Toxicity of the Pesticides Difenoconazole and Dimethomorph on Embryonic Zebrafish}

\author{
Ruiqi Fan ${ }^{1,2}$, Wanjun Zhang ${ }^{1,2}$, Li Jia ${ }^{1}$, Lizhong Li $^{1}$, Jun Zhao ${ }^{1}$, Zengming Zhao ${ }^{1}$, Shuangqing Peng ${ }^{1}$, \\ Yiqiang Chen ${ }^{2}$ and Xiaoyan Yuan $1,3, *$ \\ 1 Center of Disease Control and Prevention, PLA, Beijing 100073, China; fanruiqi94110@cau.edu.cn (R.F.); \\ s20193040574@cau.edu.cn (W.Z.); acegi@163.com (L.J.); lilizhongali@126.com (L.L.); \\ tangsong009@126.com (J.Z.); zhaozm000@163.com (Z.Z.); pengsq@hotmail.com (S.P.) \\ 2 State Key Laboratory of Animal Nutrition, College of Animal Science and Technology, \\ China Agricultural University, Beijing 100193, China; yqchen@cau.edu.cn \\ 3 School of Nursing and Health, Henan University, Kaifeng 475000, China \\ * Correspondence: yanziyuan2007@126.com
}

Citation: Fan, R.; Zhang, W.; Jia, L.; Li, L.; Zhao, J.; Zhao, Z.; Peng, S.; Chen, Y.; Yuan, X. Combined Developmental Toxicity of the Pesticides Difenoconazole and Dimethomorph on Embryonic Zebrafish. Toxins 2021, 13, 854. https://doi.org/10.3390/ toxins13120854

Received: 24 October 2021 Accepted: 23 November 2021 Published: 1 December 2021

Publisher's Note: MDPI stays neutral with regard to jurisdictional claims in published maps and institutional affiliations.

Copyright: ( $\odot 2021$ by the authors. Licensee MDPI, Basel, Switzerland. This article is an open access article distributed under the terms and conditions of the Creative Commons Attribution (CC BY) license (https:// creativecommons.org/licenses/by/ $4.0 /)$.

\begin{abstract}
Difenoconazole (DIF) and dimethomorph (DIM) are widely used pesticides frequently detected together in environmental samples, so the deleterious effects of combined exposure warrant detailed examination. In this study, the individual and combined effects of DIM and DIF on conventional developmental parameters (hatching rate, deformity rate, lethality) and gene expression were measured in embryonic zebrafish. Both DIF and DIM interfered with normal zebrafish embryo development, and the most sensitive toxicity index for both was $96 \mathrm{~h}$ post-fertilization (hpf) deformity rate (BMDL 10 values of 0.30 and $1.10 \mathrm{mg} / \mathrm{L}$, respectively). The combination of DIF and DIM had mainly synergistic deleterious effects on $96 \mathrm{hpf}$ deformity and mortality rates. Transcriptome analysis showed that these compounds markedly downregulated expression of mcm family genes, $c d k 1$, and $c d c 20$, thereby potentially disrupting DNA replication and cell cycle progression. Enhanced surveillance for this pesticide combination is recommended as simultaneous environmental exposure may be substantially more harmful than exposure to either compound alone.
\end{abstract}

Keywords: difenoconazole; dimethomorph; combination; transcriptomics; environmental toxicity; pesticide

Key Contribution: Difenoconazole and dimethomorph alone or combined disrupted zebrafish development; synergism was associated with mutual inhibition of $m c m ; c d k 1$; and $c d c 20$ genes.

\section{Introduction}

Difenoconazole (DIF) is a broad-spectrum triazole fungicide used globally to protect crops and seeds, and is generally considered safe for humans and mammals. However, recent studies have reported apparent toxic effects on aquatic animals such as Daphnia magna and zebrafish; the concentration of tested DIF ranged from 0.67 to $4.73 \mathrm{mg} / \mathrm{L}$ [1,2]. Besides, increased adult mortality, suppression of embryonic heart rate, and delayed embryonic development of DIF were also found; such effects can be seen within 0.18 to $1.47 \mathrm{mg} / \mathrm{L}$ [3]. These effects may result from dysregulation of genes controlling embryonic development and retinoic acid metabolism [4] as well as from the induction of cellular oxidative stress [5]. Residual DIF is often detected in crops as well as the surrounding soil, for example, $0.103-0.520 \mathrm{mg} / \mathrm{kg}$ in soil for mango in China, and $0.14-0.32 \mathrm{mg} / \mathrm{kg}$ in Italy $[6,7]$. Although there are four stereoisomers of difenoconazole, the toxicity data of different isomers are still lacking, and the existing reports temporarily do not consider the toxic effects of different isomers [8]. Given these reports of developmental toxicity, further studies are warranted on the dangers of DIF to ecosystems and human health.

Dimethomorph (DIM) is another broad-spectrum fungicide of the morpholine class with demonstrated efficacy against fungal spores. Thus, like DIF, DIM is used widely for 
the cultivation of fruits and vegetables. However, DIM residue has been detected in the surrounding environment of planted grapes within the range of $0.05-0.19 \mathrm{mg} / \mathrm{kg}$ [9], so the potential risks of DIM exposure should be evaluated. Also, considering the high rate of co-detection with DIF $[10,11]$ and the potential for synergistic effects, comprehensive risk assessment requires evaluation of joint DIM plus DIF toxicity.

For instance, reports have confirmed that DIF, tebuconazole, and propiconazole in certain proportions can exert synergistic deleterious effects on zebrafish [3]. Similarly, diclofop-methyl and DIF can alter the biochemical parameters of oxidative stress in albino rats to a greater extent than equivalent concentrations of either compound alone [12]. However, the combined toxicity of DIF plus DIM exposure and the underlying mechanisms have not been studied. Transcriptomics is a valuable method for studying the underlying changes in gene expression associated with chemical toxicity, including the joint toxicity of various chemical combinations $[13,14]$.

In this study, we analyzed the combined effects of DIF and DIM on zebrafish embryonic development and used transcriptomics to identify DEGs (differentially expressed genes). And qPCR method was implemented for validation of the genes altered by these compounds individually and in combination. These results suggest that DIF and DIM may have synergistic toxic effects, and their potential joint risks require more in-depth researches.

\section{Results}

\subsection{Toxicity of DIF on Zebrafish Embryos}

DIFexposure had deleterious effects on multiple developmental parameters in zebrafish embryos (Figure 1), including $\mathrm{LC}_{50}$ at $96 \mathrm{hpf}$ in $1.15 \mathrm{mg} / \mathrm{L}$ and $\mathrm{EC}_{50}$ of deformity at $96 \mathrm{hpf}$ in $1.99 \mathrm{mg} / \mathrm{L}$; all eggs were dead by $48 \mathrm{hpf}$ at $5.00 \mathrm{mg} / \mathrm{L}$. DIF also altered $24 \mathrm{hpf}$ tail flicks and $48 \mathrm{hpf}$ heart rate, with enhancement at low concentrations and inhibition at high concentrations (Figure 1A, B). In addition, DIF inhibited hatching rate at $48 \mathrm{hpf}$, with complete inhibition at doses $\geq 1.58 \mathrm{mg} / \mathrm{L}$ (Figure 1C). According to BMDL $\mathrm{B}_{10}$ (Lower confidence limit of benchmark dose 10) values, the $96 \mathrm{hpf}$ deformity rate was the most sensitive index of DIF toxicity $\left(\mathrm{BMDL}_{10}=0.30 \mathrm{mg} / \mathrm{L}\right.$ ), followed by $48 \mathrm{hpf}$ hatching rate $\left(\mathrm{BMDL}_{10}=0.40 \mathrm{mg} / \mathrm{L}\right)$ and $48 \mathrm{hpf}$ heart rate $\left(\mathrm{BMDL}_{10}=0.54 \mathrm{mg} / \mathrm{L}\right)$, while $96 \mathrm{hpf}$ lethality rate $\left(\mathrm{BMDL}_{10}=0.71 \mathrm{mg} / \mathrm{L}\right)$ and $24 \mathrm{hpf}$ autonomous movement $\left(\mathrm{BMDL}_{10}=1.89 \mathrm{mg} / \mathrm{L}\right)$ were substantially less sensitive (see Table S2). 


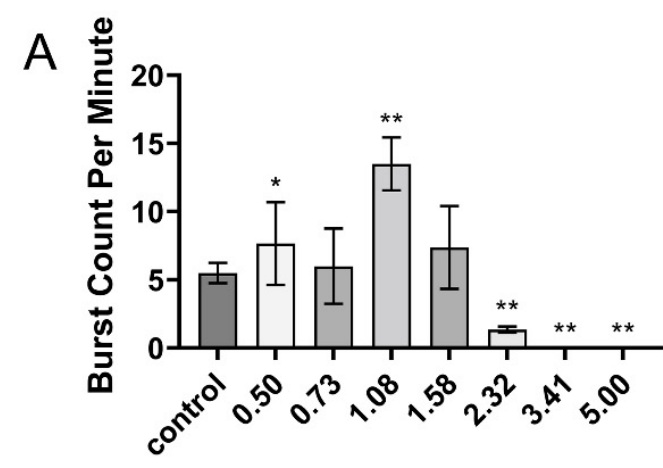

Concentration (mg/L)

C

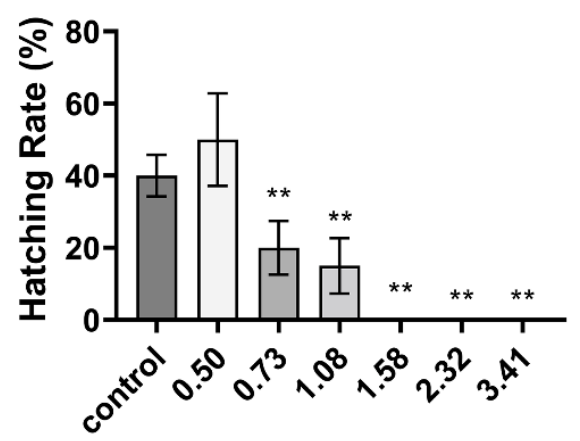

Concentration $(\mathrm{mg} / \mathrm{L})$

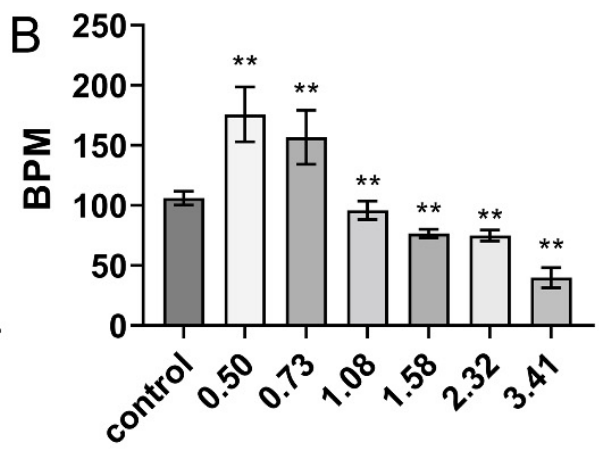

Concentration (mg/L)

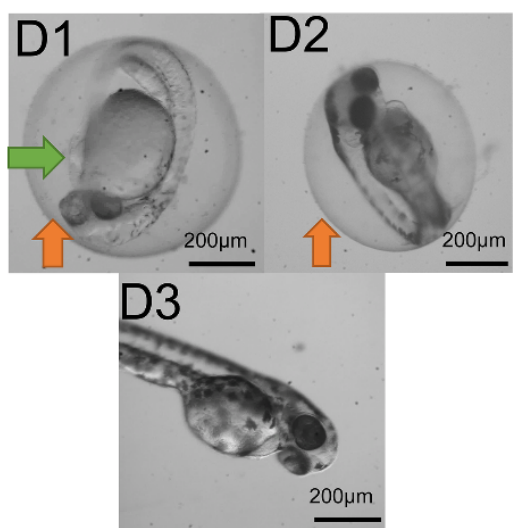

Figure 1. Effects of DIF on zebrafish embryo development. (A): Effect on tail flickstail flicks (bursts per $\min$ ) at $24 \mathrm{hpf}$ ( $n=15$ for each concentration). (B): Effect on larval heart rate (in beats per min [bpm]) at $48 \mathrm{hpf}$ ( $n=15$ for each concentration). (C): Effect on hatching rate at $48 \mathrm{hpf}$ (analyzed in triplicate). Data in (A-C) are shown as mean \pm SEM; ${ }^{*} p<0.05,{ }^{* *} p<0.01$ [one-way ANOVA, Tukey's Honestly Significant Difference test (Tukey's HSD)]. D: Typical deformities caused by DIF at $48 \mathrm{hpf}$. (D1) $2.32 \mathrm{mg} / \mathrm{L}$. (D2) $1.08 \mathrm{mg} / \mathrm{L}$. (D3) $0.50 \mathrm{mg} / \mathrm{L}$. Green arrows demarcate regions of yolk sac edema, and orange arrows indicate hatching delay.

\subsection{Toxicity of DIM on Zebrafish Embryo Development}

DIM exposure also had substantial deleterious effects on multiple developmental parameters in zebrafish embryos, although at generally higher concentrations than DIF (Figure 2). For instance, the $96 \mathrm{hpf} \mathrm{EC}_{50}$ of deformity and $\mathrm{LC}_{50}$ were $4.25 \mathrm{mg} / \mathrm{L}$ and $11.84 \mathrm{mg} / \mathrm{L}$, respectively, markedly higher than the corresponding values for DIF. Besides, all eggs were dead by $48 \mathrm{hpf}$ at the highest concentration. Like DIF, DIM also enhanced $24 \mathrm{hpf}$ autonomous movement and $48 \mathrm{hpf}$ larvae heart rate at low concentrations but inhibited these metrics at higher concentrations. Conversely, DIM inhibited $48 \mathrm{hpf}$ hatching rate at low concentrations $(2.00-2.94 \mathrm{mg} / \mathrm{L})$ and enhanced hatching rate at high concentrations (Figure 2C). According to $\mathrm{BMDL}_{10}$ values, $96 \mathrm{hpf}$ deformity rate was the most sensitive index of developmental toxicity $\left(\mathrm{BMDL}_{10}=1.10 \mathrm{mg} / \mathrm{L}\right)$, followed by $48 \mathrm{hpf}$ heart rate $\left(\mathrm{BMDL}_{10}=2.31 \mathrm{mg} / \mathrm{L}\right), 96 \mathrm{hpf}$ lethality rate $(4.10 \mathrm{mg} / \mathrm{L}), 48 \mathrm{hpf}$ hatching rate $(5.92 \mathrm{mg} / \mathrm{L})$, and $24 \mathrm{hpf}$ tail flicks (7.90 mg/L) (Supplementary Materials Table S2). In general, DIM alone was less toxic to zebrafish embryos than DIF, and the BMDL 10 value of the most sensitive index was about 3.5 times higher than the corresponding value for DIF. 


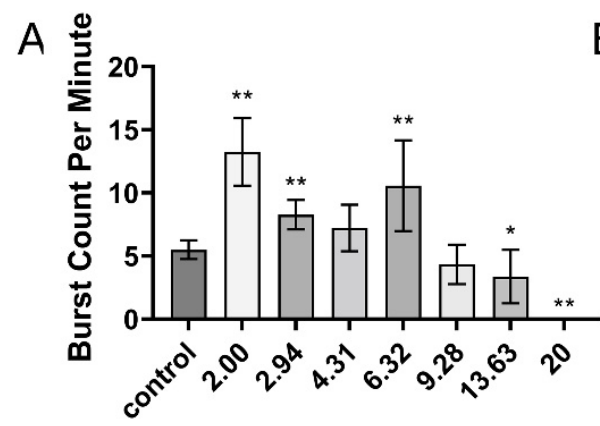

Concentration (mg/L)

C

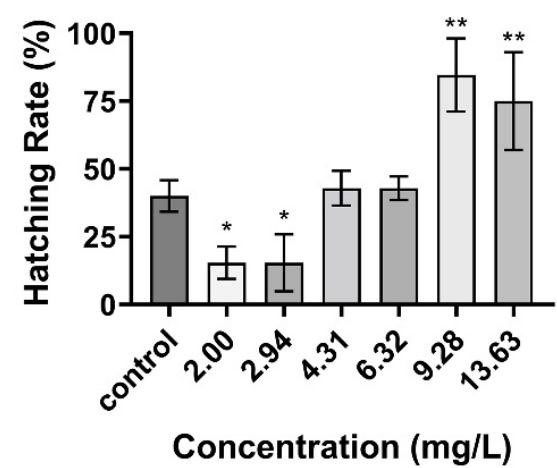

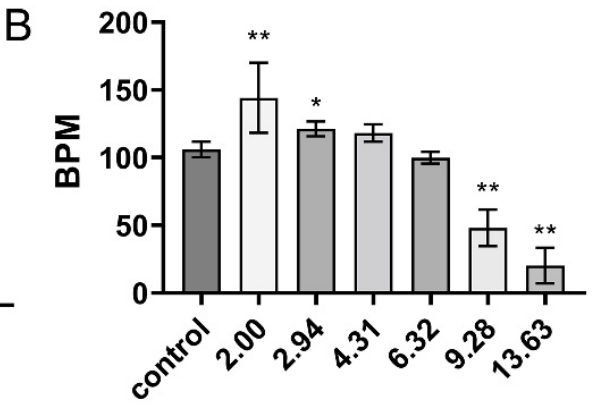

Concentration (mg/L)

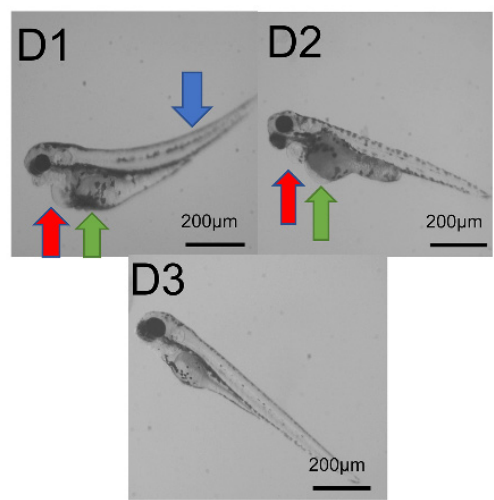

Figure 2. Effects of DIM on zebrafish developmental parameters. (A): Effect on tail flicks at $24 \mathrm{hpf}$ ( $n=15$ for each concentration). (B): Effect on larval heart rate at $48 \mathrm{hpf}$ ( $n=15$ for each concentration).

(C): Effect on hatching rate at $48 \mathrm{hpf}$ (analyzed in triplicate). Data in (A-C) are shown as mean $\pm \mathrm{SEM}$; ${ }^{*} p<0.05,{ }^{* *} p<0.01$ (ANOVA, Tukey's HSD). D: Typical deformities caused by DIM at 48 hpf. (D1) $13.63 \mathrm{mg} / \mathrm{L}$. (D2) $4.31 \mathrm{mg} / \mathrm{L}$, (D3) $2.00 \mathrm{mg} / \mathrm{L}$. Red arrows demarcate areas of pericardial edema, green arrows yolk sac edema, and blue arrows spinal curvature.

\subsection{Toxicity of Combined Exposure to DIF and DIM}

Combined exposure to both pesticides also induced significant dose-dependent reductions in $24 \mathrm{hpf}$ tail flicks, $48 \mathrm{hpf}$ heart rate, and $48 \mathrm{hpf}$ hatching rate (Figure $3 \mathrm{~A}-\mathrm{C}$ ). The dose-deformity and dose-lethality curves yielded a 96-hpf $\mathrm{EC}_{50}$ of deformity of $3.47 \mathrm{mg} / \mathrm{L}$ and a 96-hpf $\mathrm{LC}_{50}$ of $4.20 \mathrm{mg} / \mathrm{L}$, respectively. All eggs were dead by $48 \mathrm{hpf}$ at the highest concentration so that the data of 48 -hpf heart beat at $13.63 \mathrm{mg} / \mathrm{L}$ was missing. Unlike single pesticide exposure, the most sensitive indicator of mixed exposure was $48 \mathrm{hpf}$ heart rate $\left(\mathrm{BMDL}_{10}=0.18 \mathrm{mg} / \mathrm{L}\right)$, followed by 48 -hpf hatching rate $\left(\mathrm{BMDL}_{10}=1.37 \mathrm{mg} / \mathrm{L}\right)$, $96 \mathrm{hpf}$ lethality rate $(1.55 \mathrm{mg} / \mathrm{L}), 96 \mathrm{hpf}$ deformity rate $(2.74 \mathrm{mg} / \mathrm{L})$, and $24 \mathrm{hpf}$ tail flicks (5.90 mg/L) (Supplementary Materials Table S2). The $48 \mathrm{hpf}$ heart rate was a markedly more sensitive index of toxicity under combined treatment than under treatment with either compound alone. 

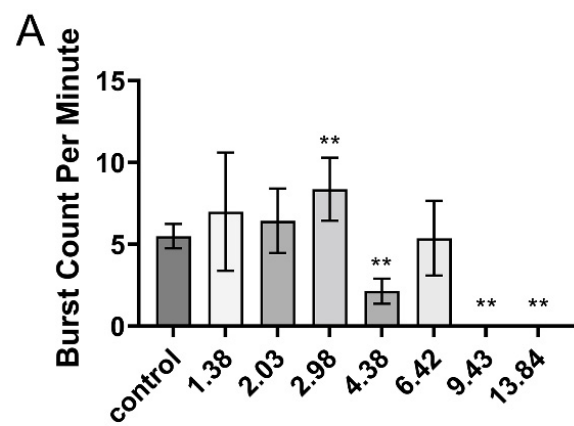

Concentration (mg/L)

C

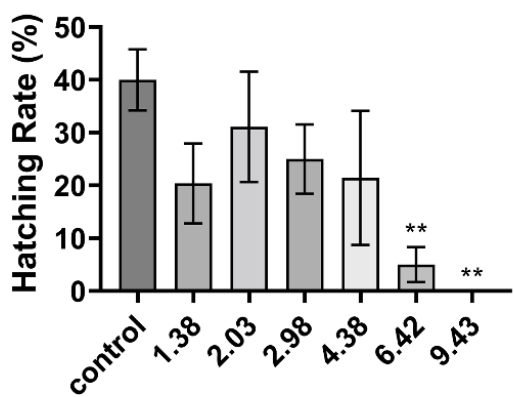

Concentration (mg/L)

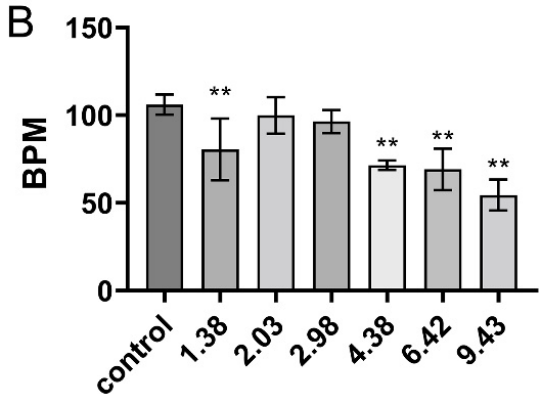

Concentration (mg/L)

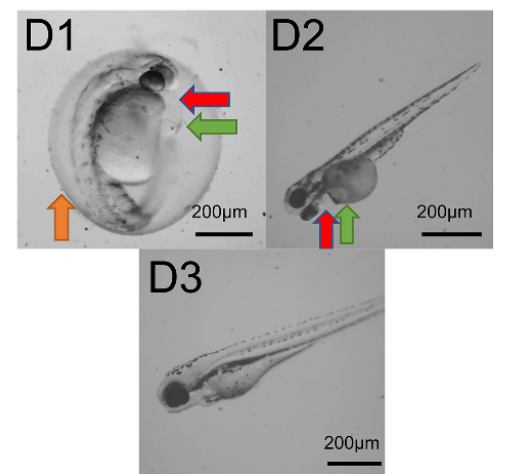

Figure 3. Effects of combined DIF and DIM exposure (MIX) on developmental parameters. (A): Effect on tail flicks at $24 \mathrm{hpf}$ ( $n=15$ for each concentration). (B): Effect on larval heart rate at $48 \mathrm{hpf}(n=15$ for each concentration). (C): Effect on hatching rate at $48 \mathrm{hpf}$ (analyzed in triplicate). Data in (A-C) are shown as mean \pm SEM; ${ }^{* *} p<0.01$ (ANOVA, Tukey's HSD) D: Typical deformities caused by MIX at 48 hpf. (D1) $4.38 \mathrm{mg} / \mathrm{L}$. (D2) $2.03 \mathrm{mg} / \mathrm{L}$. (D3) $1.38 \mathrm{mg} / \mathrm{L}$. Red arrows demarcate areas of pericardial edema, green arrows demarcate areas of yolk sac edema, and orange arrows indicate hatching delay.

\subsection{Synergistic Effects of Combined DIF and DIM on Developmental Parameters}

Combination indices (CI values) were calculated from single-drug and mixed exposure data to assess concentration-dependent antagonistic, additive, and synergistic interactions of DIF and DIM. As shown in Figure 4, the two compounds exhibited synergy on hatching rate at low effect levels ( $0-20 \%$ ) as indicated by CI values $<0.9$ but antagonism at effect levels $>20 \%$ as indicated by CI values $>1.1$. The CI values of MIX for deformity and lethality rates were within the additive CI range at low effect levels but indicated mild synergy at high effect levels (15-100\% for combined death rate, 55-100\% for combined deformity rate).

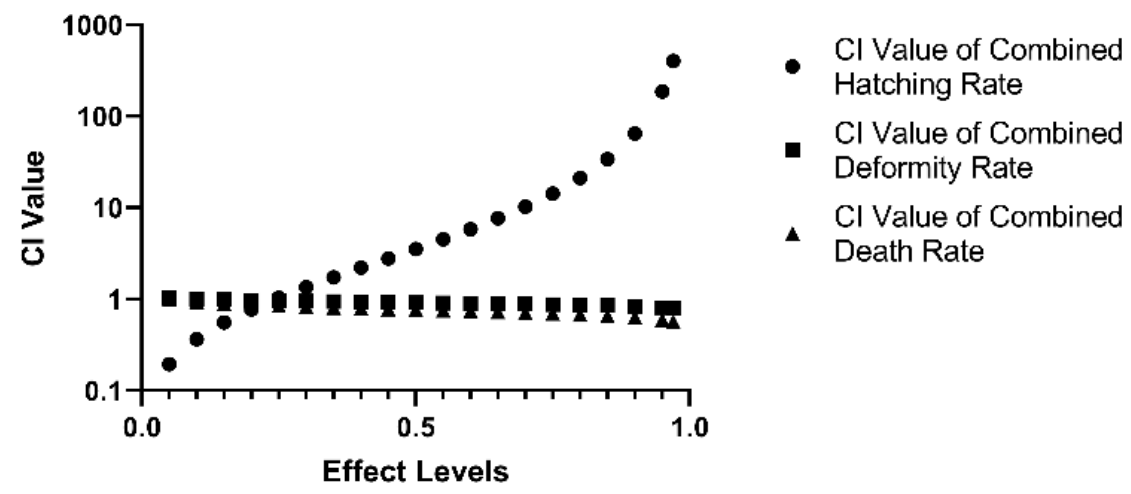

Figure 4. Combination index (CI) values of MIX for hatching rate (circle), deformity rate (square), and death rate (triangle). 
2.5. Transcriptomic and qPCR Analyses of Differentially Expressed Genes under DIF, DIM, and Combined Treatment

The results of RNA-Seq revealed 4409 differentially expressed genes (DEGs) following DIF treatment, including 1749 upregulated and 2660 downregulated genes. In comparison, DIM induced relatively few DEGs, with only 101 upregulated and 74 downregulated genes. In the MIX treatment group, 1322 DEGs were upregulated and 2000 were downregulated. We then focused on the 79 genes modulated by both single exposure and mixed exposure given the synergist effects of these two compounds on deformity and mortality rates. The DEGs common in the DIF, DIM, and MIX groups were enriched, and then compared to the Kyoto Encyclopedia of Genes and Genomes (KEGG) pathways. 'DNA replication' and 'cell cycle mismatch repair' were the most enriched pathways (Figure 5A), including the mini-chromosome maintenance $(\mathrm{mcm})$ family genes $m c m 2, m c m 3, m c m 4$, and $m c m 6$, the cell cycle regulators $c d k 1$ and $c d c 20$, and the mismatch repair genes msh6 and pold1. Gene Ontogeny (GO) analysis also revealed that the DEGs common in the DIF, DIM, and MIX groups were enriched in genes associated with 'DNA replication', 'MCM protein function', and other aspects of biological function (Figure 5B).

The identities of shared DEGs were further confirmed by qPCR. Both DIF and DIM as well as the combination (MIX group) downregulated the expression levels of $m c m 2, m c m 3$, and $m c m 4$. While DIM alone had no effect on the expression levels of $c d k 1$ and $c d c 20$, it potentiated the downregulation of both genes induced by DIF. Moreover, DIF and DIM also synergistically downregulated multiple genes related to DNA replication and cell cycle control, such as ccnb1, msh6, and pold1 (Figure 6A). The correlation between qPCR and RNA-Seq was also checked, and the Pearson R square was 0.6656 , which indicated a strong correlation (Figure 6B). 


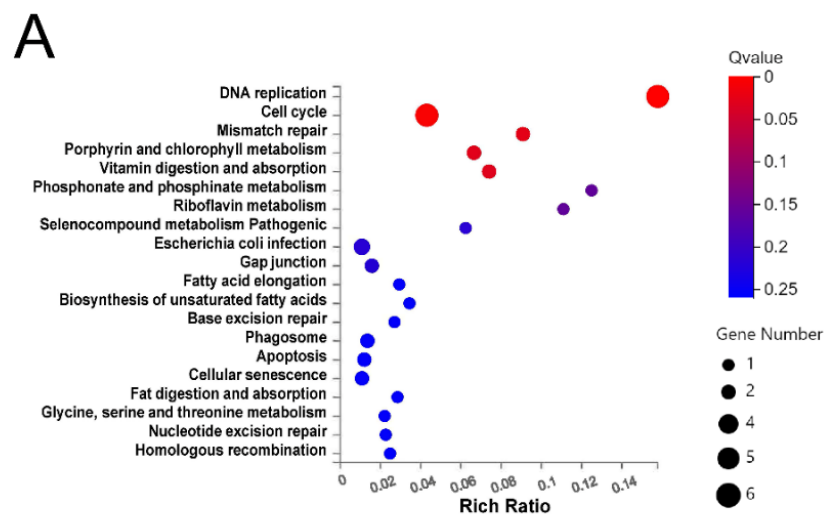

B
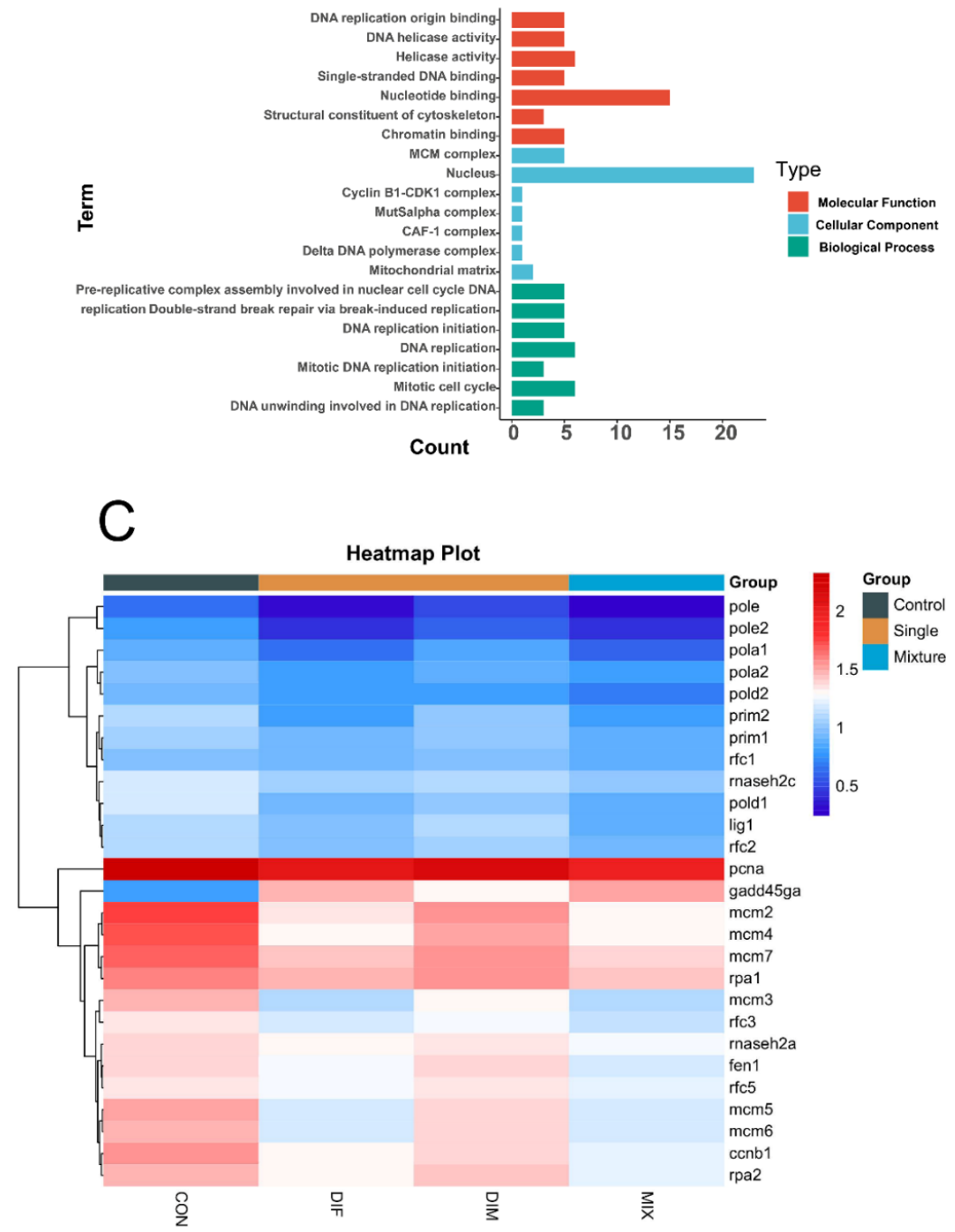

Figure 5. Differentially expressed genes (DEGs) in zebrafish embryos following DIF, DIM, and combined treatment. (A): KEGG pathway enrichment of common differentially expressed genes in DIF, DIM, and MIX. (B): GO enrichment of common DEGs in DIF, DIM, and MIX. (C): Heat map of top DEGs. 

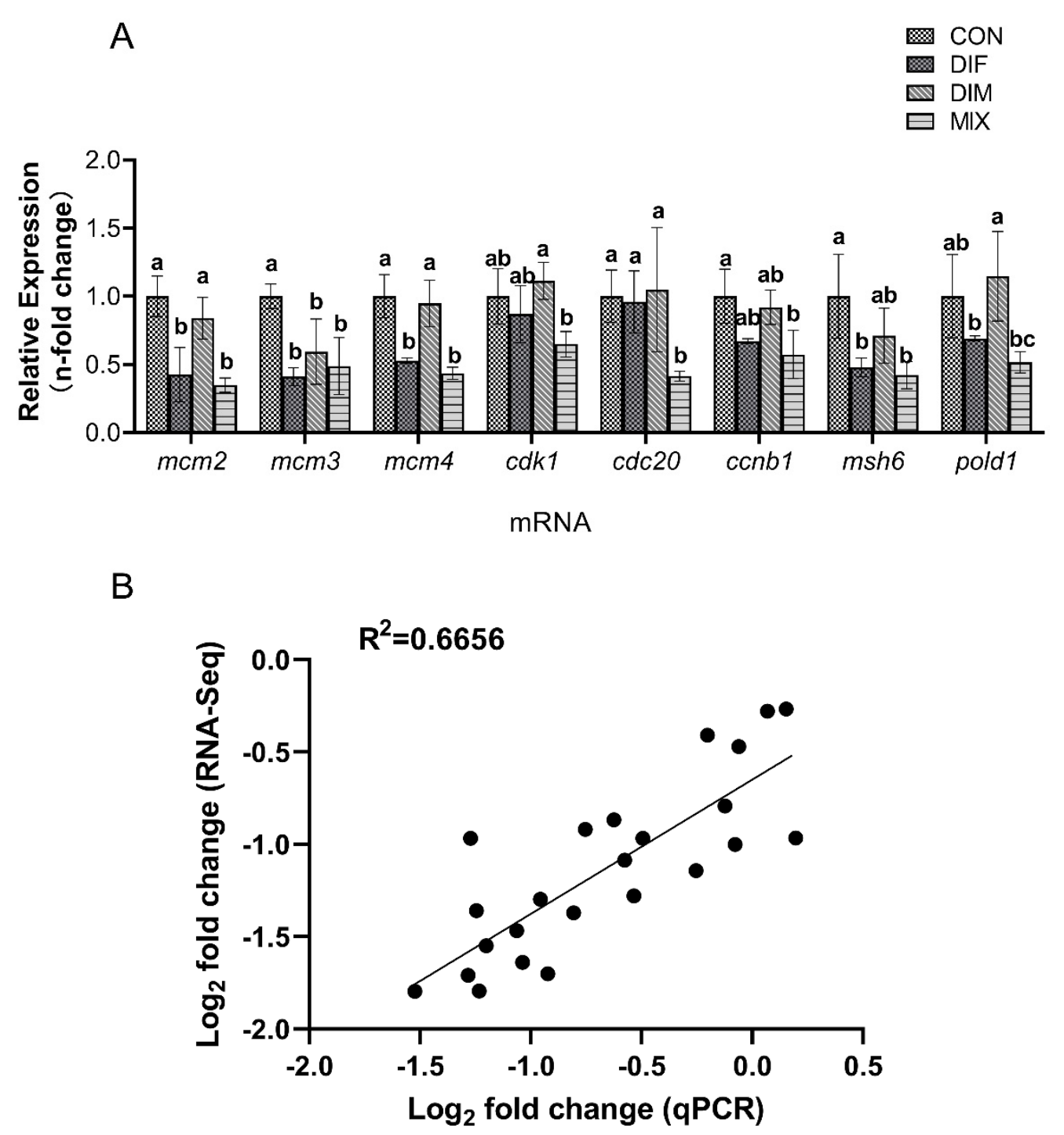

Figure 6. Validation of transcriptomic by qPCR. Genes related to cell cycle and DNA replicate were selected for the validation by using qPCR. (A): Relative mRNA expression levels of genes differentially modulated by DIF, DIM, and the combination (MIX). All samples were extracted and analyzed in triplicate. Data are shown as mean \pm SEM; lowercase letters were used to reveal the differences, completely different lowercase letters above the bars indicate significant differences $(p<0.05)$, while any of the same lowercase letters indicate no significant difference $(p>0.05)$. (B): The correlation between transcriptomic analysis and $\mathrm{PPCR}$, the higher R square value reveals the greater correlation. The X-axis represents log2-fold change in the expression levels found by qRT-PCR. The Y-axis represents the log2 value of the expression level fold change from RNA-Seq.

\section{Discussion}

Widespread application of DIFand DIM to protect crops has increased the risks of mixed environmental contamination and simultaneous exposure. Residual concentrations of DIF have been detected in both soil and water samples from India and Brazil, the concentrations detected can be up to $35 \mu \mathrm{g} / \mathrm{L}$ in irrigation water and $1.5 \mathrm{mg} / \mathrm{kg}$ in soil $[15,16]$. In some provinces of China, DIF concentrations as high as $1.00-2.36 \mathrm{mg} / \mathrm{kg}$ have been measured in paddy water [17], which is even higher than the $96 \mathrm{hpf}$ LC50 for zebrafish embryos measured in the present study. Similarly, DIM concentrations from $0.20 \mathrm{mg} / \mathrm{kg}$ [18] to $0.70 \mathrm{mg} / \mathrm{kg}$ [9] have been reported. Further, DIM has a long elimination half-life in soil [19] and can enter groundwater [20] through leaching. Thus, environmental and health risk assessments are warranted.

Calculation of the combination index (CI) for DIF plus DIM (MIX) revealed synergistic effects on mortality and teratogenicity $(\mathrm{CI}<0.9)$ within the high-dose effect range. In addi- 
tion, the $\mathrm{BMDL}_{10}$ values of MIX for tail flicks and heart rate were lower than the weighted averages of the individual-agent $\mathrm{BMDL}_{10}$ values, suggesting that the risk threshold concentration for mixed exposure may be lower than that of individual exposure. EuroMix and other projects focusing on the health risks of multi-component pollutant exposure [21] have found several examples of increased risk from combined pollutants compared to the individual components [22]. The findings of this study suggest that DIF and DIM may have a synergistic toxic effect and more researches are needed for environmental health risk assessment of combined exposure to these two pesticides.

The toxicity of DIF has been extensively investigated. Zhu et al. found that DIF caused cardiotoxicity by inducing oxidative stress and apoptosis in early life stages of zebrafish within 0.3-1.2 mg/L [5], while Teng et al. found that DIF altered amino acid and lipid metabolism in early-stage zebrafish within $0.5-500 \mu \mathrm{g} / \mathrm{L}$ [23]. In contrast, we found that DIF reduced the expression levels of multiple genes related to DNA replication and cell cycle regulation, potentially accounting for the significant disruption of embryonic development and survival. Teng et al. reported parental exposure to DIF at environmentally relevant exposure concentrations could induce detrimental response in the offspring by disruption of sex steroid hormones and vitellogenin [24]. Therefore, it is possible that adverse response is ultimately impaired by a combination of oxidative stress, dysregulation of cell proliferation, and aberrant endocrine signaling.

In contrast to DIF, there have been relatively few studies on DIM toxicity. Regueiro et al. reported cytotoxicity against primary cultured cortical neurons after exposure to $0.1-100 \mu \mathrm{M}$ DIM for 7 days [25], providing a potential explanation for the observed disruptions in zebrafish motor activity and heart rate regulation. The overall developmental toxicity of DIM was lower than that of DIF, suggesting less risk from DIM exposure alone. However, analysis of combined exposure suggested that DIM may amplify DIF developmental toxicity.

DNA replication influences all aspects of development and maturation. In zebrafish, about $20 \%$ of all cells are undergoing DNA replication at $6 \mathrm{hpf}$ [26]. Thus, the effects of DIF and DIM on DNA replication may disrupt all subsequent stages of development. Similarly, cell cycle regulation is critical during early development. For instance, the developmental toxicity of silver nanoparticles was attributed to cell cycle arrest and upregulation of genes such as ccna1 and stag3 [27], which suggests that the cell cycle affected by chemicals may attribute to the toxicity effects

Genes of the $\mathrm{mcm}$ family were among the most frequently and severely dysregulated by DIF, DIM, and MIX. These genes encode minichromosome maintenance (MCM) proteins that control DNA replication by regulating checkpoint signaling pathways [28]. MCM proteins are also markers of proliferation zones during embryogenesis [29], so reduced function concomitant with gene downregulation may disrupt the proper patterning of cell amplification. Hou et al. found that the toxicity of Nano-ZnO on zebrafish was associated with effects on the expression levels of $m \mathrm{~cm}$ family genes [30], which suggests that the $\mathrm{mcm}$ genes may be related to the adverse effects of chemicals on zebrafish. Moreover, $\mathrm{mcm}$ genes are involved in large regulatory networks, so both DIF and DIM may have broader biological effects that warrant further investigation.

In addition to $m \mathrm{~cm}$ genes, both DIM and DIF altered expression levels of the cell cycle regulatory genes cyclin-dependent kinase $1(\mathrm{cdk} 1)$ and cell division cycle protein 20 (cdc20). The cell cycle is tightly regulated to promote correct morphological development during growth [31]. In addition to malformation, dysregulation of the cell cycle and related functions may cause cell proliferation to stagnate and increase mortality [32].

Inhibition of CDK1 may enhance cellular sensitivity to DNA damage [33]. Li et al. also found that the fungal toxin zearalenone damaged porcine granulosa cells by altering the expression of $c d k 1$ and related genes [34]. In addition, the pesticide glyphosate altered CDK1 function in sea urchin embryonic cells [35]. Thus, disruption of normal $c d k 1$ expression may contribute to the toxicity of many distinct compounds. Similarly, dysregulation of $c d c 20$ expression may induce cell damage. Mansur et al. found that bisphenol A significantly inhibited CDC20 expression in human cumulus cells [36]. Chou et al. also found that 
the toxic effect of phenethyl isothiocyanate against human glioblastoma GBM 8401 cells was associated with CDC20 downregulation [37]. Although there have been a number of reports on chemical toxicity mediated by dysregulation of $c d k 1$ or $c d c 20$, all were in vitro models. Here we demonstrate that DIM and DIF can also disrupt the regulation of $c d k 1$ and $c d c 20$ expression levels in zebrafish embryos, which may in turn contribute to the developmental toxicity of these compounds.

Although the expression of most genes was within two-fold change compared to the control group, the selected genes showed a strong correlation with the results of the transcriptome (Pearson $R^{2}=0.6656$ ), indicating these sites in DNA replication and cell cycle related pathways had been affected. Considering that the dose selected in the experiment was $\mathrm{BMDL}_{10}$, a point of departure, the toxic effect may not be relatively obvious. Therefore, it was a possible phenomenon that the fold-change of mRNA expression was within 2 . Similar results can be found in several studies [38,39]. In summary, $m c m$ family genes, $c d k 1$ and $c d c 20$ may serve as sensitive sites for the embryonic developmental toxicity of DIFand DIM, but more dose-effect experiments are needed to explore further.

\section{Conclusions}

This study confirmed that DIF could affect the developmental parameters of zebrafish within the range of $0.50-5.00 \mathrm{mg} / \mathrm{L}$, and DIM could also affect developmental parameters of zebrafish within the range of $2.00-20.00 \mathrm{mg} / \mathrm{L}$. The combination of DIF and DIM had mainly synergistic deleterious effects on $96 \mathrm{hpf}$ deformity and mortality rates. Transcriptome analysis showed that these compounds markedly downregulated expression of $\mathrm{mcm}$ family genes, $c d k 1$, and $c d c 20$, thereby potentially disrupting DNA replication and cell cycle progression. These findings also further highlight the utility of transcriptomics to reveal potential mechanisms underlying the synergistic effects of various toxin combinations. More extensive surveillance of this fungicide combination in agriculture and environment samples appears warranted for comprehensive risk assessment of DIF and DIM exposure.

\section{Materials and Methods}

5.1. Reagents

Difenoconazole (purity: 99.9\%, CAS Number: 119446-68-3) and dimethomorph (purity: 98.7\%, CAS Number: 110488-70-5) were purchased from Dr. Ehrenstorfer GmbH (Augsburg, Germany), and DMSO (purity: 99.7\%, LC-MS Grade) was purchased from Thermo Fisher (Waltham, MA, USA). Other reagents (analytical grade) were purchased from Shanghai Sinopharm Chemical Reagent (Shanghai, China).

\subsection{Maintenance and Breeding of Zebrafish}

Use of Laboratory Animals and approved by the Animal Welfare and Animal Experimental Ethical Committee at the China Agricultural University (Beijing, China) (certification no: AW11111208-1-1). Wild-type Tu zebrafish were purchased from Wuhan Zebrafish Resource Center (Wuhan, China) and housed in a dedicated aquatic system (ESEN Technology, Beijing, China). The light and dark cycle was controlled at $14 \mathrm{~h} / 10 \mathrm{~h}$ and room temperature at $28 \pm 2{ }^{\circ} \mathrm{C}$. Fish were fed freshly hatched brine shrimp larvae twice daily. In the afternoon before experiments, two male and two female fish were placed in separate compartments of a breeding box. At the beginning of the photoperiod the following day, the partitions were removed to allow the males and females to chase freely. After mating, the fertilized eggs were collected within $30 \mathrm{~min}$. To remove unfertilized, coagulated, and damaged eggs, collected eggs were examined under an SZ-10 stereomicroscope (Olympus, Japan). Then, the eggs were kept at $28^{\circ} \mathrm{C}$ until the experiment began.

\subsection{Pesticide Exposure}

Pesticides were weighed, dissolved in LC-MS grade DMSO as stock solutions, and diluted in Holt buffer (containing $\mathrm{NaCl} 3.5 \mathrm{~g} / \mathrm{L}, \mathrm{KCl} 0.05 \mathrm{~g} / \mathrm{L}, \mathrm{CaCl}_{2} 0.1 \mathrm{~g} / \mathrm{L}, \mathrm{NaHCO}_{3}$ $0.05 \mathrm{~g} / \mathrm{L})$ to the indicated treatment concentrations. The final concentration of DMSO 
was $0.1 \%$, which had no effects on developmental parameters in preliminary experiments. The final DIF concentrations were $0.50,0.73,1.08,1.58,2.32,3.41$, and $5.00 \mathrm{mg} / \mathrm{L}$, and the final DIM concentration were 2.00, 2.94, 4.31, 6.32, 9.28, 13.63, and $20.00 \mathrm{mg} / \mathrm{L}$. The mixed exposure liquid MIX (DIF: DIM = 1:5.92, $v / v$ ) was prepared according to the principle of equipotent concentration ratios. The total concentrations of MIX were 1.38, 2.03, 2.98, 4.38, 6.42, 9.43, and $13.84 \mathrm{mg} / \mathrm{L}$.

The exposure started at $4 \mathrm{hpf}$. We referred to the exposure design of Park et al. [40]. For treatment, 20 healthy eggs were placed in each well of a 6-well plate and treated with $10 \mathrm{~mL}$ of the indicated solution, with 3 replicates at each DIF, DIM, or MIX concentration. The solution was renewed every $24 \mathrm{~h}$ for $96 \mathrm{~h}$ and dead eggs were removed at each solution exchange. Embryonic mortality and malformation rates of each treatment group were recorded at $96 \mathrm{hpf}$.

\subsection{Measurement of Developmental Parameters}

Mortality as evidenced by egg coagulation or cardiac arrest was determined at 24,48 , 72 , and $96 \mathrm{hpf}$. At the same time, the rate of deformity (including pericardial edema, yolk sac edema, and tail flicks) was calculated for each treatment group at 48, 72, and $96 \mathrm{hpf}$, the temperature was kept at $28 \pm 2{ }^{\circ} \mathrm{C}$ during all measurements. The hatching rate, defined as total separation of juvenile fish from the egg membrane, was calculated at $48 \mathrm{hpf}$. Five embryos in one replicate were selected and recorded under a stereoscopic microscope for $1 \mathrm{~min}$ tail flicks at $24 \mathrm{hpf}$ and for 30-s heart rate at $48 \mathrm{hpf}$ using MediaRecorder4.0 (Noldus, Wageningen, The Netherlands). We considered a tail flick as a movement more significant than 15 pixels recorded by the software. The heart rate values were multiplied by 2 and converted to beats per minute. Video records were digitized for analysis using DanioScope 1.1 (Noldus, Wageningen, The Netherlands). The effects of pesticide exposure are expressed as $10 \%$ benchmark dose levels (BMDL 10 values). For tail flicks and heart beat measurements, only alive eggs or larvae were tested. The hatching rates were calculated by dividing the number of hatched eggs by the number of all the alive eggs and larvae.

\subsection{Transcriptomics}

For gene expression analyses, fertilized eggs were treated as indicated starting at $4 \mathrm{hpf}$ until $96 \mathrm{hpf}$, with 3 biological replicates per treatment group and 80 eggs in each replicate. After $96 \mathrm{hpf}, 40$ fertilized eggs of each replicate were transferred to a 2-mL centrifuge tube, and the supernatant separated by centrifugation at $12,000 \times g$ and $4{ }^{\circ} \mathrm{C}$. Eggs were then washed twice with $1 \mathrm{~mL} 1 \times$ phosphate-buffered saline (PBS) with centrifugation after each wash to remove the supernatant. Total RNA was extracted from washed eggs using Trizol according to the manufacturer's instructions (Ambion, Waltham, MA, USA) and stored at $-80^{\circ} \mathrm{C}$ until transcriptomics analysis using BGI-Seq (see detailed protocol in the Supplementary Materials). The transcriptome raw data have been submitted to NCBI database with the BioProject number PRJNA780940.

\subsection{Real-Time Quantitative Reverse Transcription PCR}

RNA was extracted from the remaining eggs of each replicate using Trizol as described and reverse transcribed using a commercial kit (Thermo Scientific, Waltham, MA, USA). Gene expression levels were estimated using an LightCycler480 II thermocycler and 2X SG Fast qPCR Master Mix (Roche, Basel, Switzerland), and the primer sequences listed in the Supplementary Materials. The reaction volume was $25 \mu \mathrm{L}$, and the thermocycle protocol was $95^{\circ} \mathrm{C}$ for $3 \mathrm{~min}$ as initial step, 45 cycles of $95^{\circ} \mathrm{C}$ for $5 \mathrm{~s}, 60^{\circ} \mathrm{C}$ for $30 \mathrm{~s}$, and dissociated according to instrument guidelines. Each treatment was analyzed in 3 biological replicates and each sample was tested in 3 technical replicates. Relative gene expression levels were calculated using the $2^{-\Delta \Delta C T}$ method and $\beta$-actin as the reference gene (see primer pairs of selected genes in Table S1) 


\subsection{Statistics}

All developmental parameters and LC50 values were calculated and compared using SPSS 22.0. Developmental parameters and qPCR analysis results were expressed as mean \pm standard deviation. One-way analysis of variance (ANOVA) and Tukey's test were used to compare the means of multiple groups if they passed Levene's Test. $p$-values $<0.05$ were considered to be statistically significant. Graphpad 8.0 was used to draw $96 \mathrm{hpf}$ LC curves and BMDS 3.2 software to calculate $10 \%$ benchmark dose levels (BMDL 10 values) [41]. CompuSyn 1.0.4 software [42] was used to constructe $96 \mathrm{hpf}$ concentrationlethality and concentration-deformation rate curves, and to calculate the combination index (CI) values for each developmental parameter. Transcriptomic results were analyzed using the BGI Dr.Tom online work platform (https:/ / biosys.bgi.com, accessed on 1 October 2021).

Supplementary Materials: The following are available online at https:/ /www.mdpi.com/article/ 10.3390/toxins13120854/s1, Table S1: Primer pairs of selected genes in qRT-PCR analysis; Table S2: $\mathrm{BMDL}_{10}$ of developmental parameters after exposure of difenoconazole, dimethomorph and mixture of the two; Table S3: Data generated by the zebrafish transcriptome and quality filtering; Table S4: Significantly changed KEGG pathways and related genes; Table S5: GO categories of the differentially expressed genes.

Author Contributions: Conceptualization, R.F.; methodology, R.F., W.Z.; validation, L.J., L.L.; formal analysis, W.Z., L.L.; investigation, R.F., L.J.; resources, S.P.; data curation, J.Z., Z.Z.; writing—original draft preparation, R.F.; writing—review \& editing, X.Y., Y.C.; visualization, J.Z., Z.Z.; supervision, S.P.; project administration, X.Y., Y.C.; funding acquisition, X.Y., Y.C. All authors have read and agreed to the published version of the manuscript.

Funding: This research was funded by Ministry of Science and Technology of the People's Republic of China, grant number 2018YFC1603002.

Institutional Review Board Statement: Use of Laboratory Animals were approved by the Animal Welfare and Animal Experimental Ethical Committee at the China Agricultural University (Beijing, China) (certification no: AW11111208-1-1, certification date: 10 May 2021).

Informed Consent Statement: Not applicable.

Data Availability Statement: Data will be available with permission of Ministry of Science and Technology of the People's Republic of China.

Acknowledgments: We thank openbiox community and Hiplot team (https://hiplot.com.cn, accessed on 13 October 2020) for providing technical assistance and valuable tools for data analysis and visualization.

Conflicts of Interest: The authors declare no conflict of interest.

\section{References}

1. Chen, Y.; Chen, A.; Jiang, G.; Zhuo, L.; Luo, X.; Zhang, S.; Zhang, D.; Liu, Y. Acute toxicity of difenoconazole on aquatic organism. Agrochemicals 2014, 53, 900-903.

2. Zhang, G.; Li, B.; Wang, J.; Xia, X. Acute toxicity of technical material and different formulations of difenoconazole and azoxystrobin to Ze-brafish. J. Agro-Environ. Sci. 2014, 33, 2125-2130.

3. Ge, J.; Jiang, J.; Cai, L. Study on toxicity of three kinds of triazole fungicides on zebrafish (Danio rerio). Acta Agric. Zhejiangensis 2018, 30, 744-755.

4. Mu, X.Y.; Chai, T.T.; Wang, K.; Zhu, L.Z.; Huang, Y.; Shen, G.M.; Li, Y.R.; Li, X.F.; Wang, C.J. The developmental effect of difenoconazole on zebrafish embryos: A mechanism research. Environ. Pollut. 2016, 212, 18-26. [CrossRef]

5. Zhu, J.S.; Liu, C.L.; Wang, J.Y.; Liang, Y.Y.; Gong, X.; You, L.H.; Ji, C.B.; Wang, S.L.; Wang, C.; Chi, X. Difenoconazole induces cardiovascular toxicity through oxidative stress-mediated apoptosis in early life stages of zebrafish (Danio rerio). Ecotoxicol. Environ. Saf. 2021, 216, 9. [CrossRef]

6. Zhao, F.; Zheng, X.; Lv, D.; Xie, D. Residue analysis of difenoconazole in soil for mango. J. Henan Agric. Univ. 2017, 51, 115-119.

7. Lucini, L.; Magistrati, P.; Molinari, G.P. Residues of a triazole fungicide in soil after 4 years of application to sugar beet. Water Air Soil Pollut. 2009, 202, 13-18. [CrossRef]

8. Brancato, A.; Brocca, D.; De Lentdecker, C.; Erdos, Z.; Ferreira, L.; Greco, L.; Janossy, J.; Jarrah, S.; Kardassi, D.; Leuschner, R.; et al. Modification of the existing maximum residue levels for difenoconazole in various crops. Efsa J. 2018, 16, e05143. [CrossRef] 
9. Wang, S.Y.; Zhang, Q.T.; Yu, Y.R.; Chen, Y.; Zeng, S.; Lu, P.; Hu, D.Y. Residues, dissipation kinetics, and dietary intake risk assessment of two fungicides in grape and soil. Regul. Toxicol. Pharmacol. 2018, 100, 72-79. [CrossRef]

10. Sun, L.; Huang, J.; Deng, Y.; Luo, C.; Ye, Q.; Liang, Y. Risk assessment of dietary exposure to pesticide residues in staple leaf vegetables in Guangdong Province. Food Sci. 2017, 38, 223-227.

11. Vargas, T.d.S.; Salustriano, N.d.A.; Klein, B.; Romao, W.; Campos da Silva, S.R.; Wagner, R.; Scherer, R. Fungicides in red wines produced in South America. Food Addit. Contam. Part A-Chem. Anal. Control. Expo. Risk Assess. 2018, 35, 2135-2144. [CrossRef]

12. Abd-Alrahman, S.H.; Elhalwagy, M.E.A.; Kotb, G.A.; Farid, H.; Farag, A.A.G.; Draz, H.M.; Isa, A.M.; Sabico, S. Exposure to difenoconazole, diclofop-methyl alone and combination alters oxidative stress and biochemical parameters in albino rats. Int. J. Clin. Exp. Med. 2014, 7, 3637-3646.

13. Chen, H.; Chen, K.; Qiu, X.C.; Xu, H.; Mao, G.H.; Zhao, T.; Feng, W.W.; Okeke, E.S.; Wu, X.Y.; Yang, L.Q. The reproductive toxicity and potential mechanisms of combined exposure to dibutyl phthalate and diisobutyl phthalate in male zebrafish (Danio rerio). Chemosphere 2020, 258, 13. [CrossRef]

14. Li, Y.N.; Zhang, Q.N.; Fang, J.; Ma, N.; Geng, X.; Xu, M.; Yang, H.; Jia, X.D. Hepatotoxicity study of combined exposure of DEHP and ethanol: A comprehensive analysis of transcriptomics and metabolomics. Food Chem. Toxicol. 2020, 141, 9. [CrossRef]

15. Mukhopadhyay, S.; Das, S.; Bhattacharyya, A.; Pal, S. Dissipation study of difenoconazole in/on chili fruit and soil in India. Bull. Environ. Contam. Toxicol. 2011, 87, 54-57. [CrossRef]

16. Telo, G.M.; Marchesan, E.; Zanella, R.; de Oliveira, M.L.; Coelho, L.L.; Martins, M.L. Residues of fungicides and insecticides in rice field. Agron. J. 2015, 107, 851-863. [CrossRef]

17. Wang, K.; Wu, J.X.; Zhang, H.Y. Dissipation of difenoconazole in rice, paddy soil, and paddy water under field conditions. Ecotoxicol. Environ. Saf. 2012, 86, 111-115. [CrossRef]

18. Liu, C.Y.; Wan, K.; Huang, J.X.; Wang, Y.C.; Wang, F.H. Behavior of mixed formulation of metalaxyl and dimethomorph in grape and soil under field conditions. Ecotoxicol. Environ. Saf. 2012, 84, 112-116. [CrossRef]

19. Liang, H.W.; Li, L.; Li, W.; Wu, Y.J.; Zhou, Z.Q.; Liu, F.M. Dissipation and residue of dimethomorph in pepper and soil under field conditions. Ecotoxicol. Environ. Saf. 2011, 74, 1331-1335. [CrossRef]

20. Zambito Marsala, R.; Capri, E.; Russo, E.; Bisagni, M.; Colla, R.; Lucini, L.; Gallo, A.; Suciu, N.A. First evaluation of pesticides occurrence in groundwater of Tidone Valley, an area with intensive viticulture. Sci. Total Environ. 2020, 736, 139730. [CrossRef]

21. Zilliacus, J.; Beronius, A.; Hanberg, A.; Luijten, M.; van der Voet, H.; van Klaveren, J. EuroMix handbook for mixture risk assessment. Toxicol. Lett. 2019, 314, S263.

22. Zoupa, M.; Zwart, E.P.; Gremmer, E.R.; Nugraha, A.; Compeer, S.; Slob, W.; van der Ven, L.T.M. Dose addition in chemical mixtures inducing craniofacial malformations in zebrafish (Danio rerio) embryos. Food Chem. Toxicol. 2020, 137, 111117. [CrossRef]

23. Teng, M.; Zhu, W.; Wang, D.; Qi, S.; Wang, Y.; Yan, J.; Dong, K.; Zheng, M.; Wang, C. Metabolomics and transcriptomics reveal the toxicity of difenoconazole to the early life stages of zebrafish (Danio rerio). Aquat. Toxicol. 2018, 194, 112-120. [CrossRef]

24. Teng, M.; Qi, S.; Zhu, W.; Wang, Y.; Wang, D.; Dong, K.; Wang, C. Effects of the bioconcentration and parental transfer of environmentally relevant concentrations of difenoconazole on endocrine disruption in zebrafish (Danio rerio). Environ. Pollut. 2018, 233, 208-217. [CrossRef]

25. Regueiro, J.; Olguín, N.; Simal-Gándara, J.; Suñol, C. Toxicity evaluation of new agricultural fungicides in primary cultured cortical neurons. Environ. Res. 2015, 140, 37-44. [CrossRef]

26. Kuriya, K.; Higashiyama, E.; Avşar-Ban, E.; Okochi, N.; Hattori, K.; Ogata, S.; Takebayashi, S.-i.; Ogata, M.; Tamaru, Y.; Okumura, K. Direct visualization of replication dynamics in early zebrafish embryos. Biosci. Biotechnol. Biochem. 2016, 80, 945-948. [CrossRef]

27. Kang, J.S.; Bong, J.; Choi, J.S.; Henry, T.B.; Park, J.W. Differentially transcriptional regulation on cell cycle pathway by silver nanoparticles from ionic silver in larval zebrafish (Danio rerio). Biochem. Biophys. Res. Commun. 2016, 479, 753-758. [CrossRef]

28. Cortez, D.; Glick, G.; Elledge, S.J. Minichromosome maintenance proteins are direct targets of the ATM and ATR checkpoint kinases. Proc. Natl. Acad. Sci. USA 2004, 101, 10078-10083. [CrossRef]

29. Ryu, S.; Driever, W. Minichromosome maintenance proteins as markers for proliferation zones during embryogenesis. Cell Cycle 2006, 5, 1140-1142. [CrossRef]

30. Hou, J.; Liu, H.Q.; Zhang, S.Y.; Liu, X.H.; Hayat, T.; Alsaedi, A.; Wang, X.K. Mechanism of toxic effects of Nano-ZnO on cell cycle of zebrafish (Danio rerio). Chemosphere 2019, 229, 206-213. [CrossRef]

31. Saint, R.; Wigley, P.L. Developmental regulation of the cell cycle. Curr. Opin. Genet. Dev. 1992, 2, 614-620. [CrossRef]

32. Pellegrin, P.; Menard, C.; Mery, J.; Lory, P.; Charnet, P.; Bennes, R. Cell cycle dependent toxicity of an amphiphilic synthetic peptide. FEBS Lett. 1997, 418, 101-105. [CrossRef]

33. Prevo, R.; Pirovano, G.; Puliyadi, R.; Herbert, K.J.; Rodriguez-Berriguete, G.; O’Docherty, A.; Greaves, W.; McKenna, W.G.; Higgins, G.S. CDK1 inhibition sensitizes normal cells to DNA damage in a cell cycle dependent manner. Cell Cycle 2018, 17, 1513-1523. [CrossRef]

34. Li, N.; Liu, X.-L.; Zhang, F.-L.; Tian, Y.; Zhu, M.; Meng, L.-Y.; Dyce, P.W.; Shen, W.; Li, L. Whole-transcriptome analysis of the toxic effects of zearalenone exposure on ceRNA networks in porcine granulosa cells. Environ. Pollut. 2020, 261, 114007. [CrossRef]

35. Marc, J.; Mulner-Lorillon, O.; Durand, G.; Belle, R. Embryonic cell cycle for risk assessment of pesticides at the molecular level. Environ. Chem. Lett. 2003, 1, 8-12. [CrossRef]

36. Mansur, A.; Adir, M.; Racowsky, C.; Combelles, C.M.H.; Landa, N.; Machtinger, R. Susceptibility of human cumulus cells to bisphenol a In vitro. Reprod. Toxicol. 2017, 74, 189-194. [CrossRef] 
37. Chou, Y.-C.; Chang, M.-Y.; Wang, M.-J.; Liu, H.-C.; Chang, S.-J.; Harnod, T.; Hung, C.-H.; Lee, H.-T.; Shen, C.-C.; Chung, J.-G. Phenethyl Isothiocyanate Alters the Gene Expression and the Levels of Protein Associated with Cell Cycle Regulation in Human Glioblastoma GBM 8401 Cells. Environ. Toxicol. 2017, 32, 176-187. [CrossRef]

38. Yu, K.; Li, X.; Qiu, Y.; Zeng, X.; Yu, X.; Wang, W.; Yi, X.; Huang, L. Low-dose effects on thyroid disruption in zebrafish by long-term exposure to oxytetracycline. Aquat. Toxicol. 2020, 227, 105608. [CrossRef]

39. Maharaj, S.; El Ahmadie, N.; Rheingold, S.; El Chehouri, J.; Yang, L.; Souders, C.L., II; Martyniuk, C.J. Sub-lethal toxicity assessment of the phenylurea herbicide linuron in developing zebrafish (Danio rerio) embryo/larvae. Neurotoxicology Teratol. 2020, 81, 106917. [CrossRef]

40. Park, H.; Lee, J.-Y.; Lim, W.; Song, G. Assessment of the in vivo genotoxicity of pendimethalin via mitochondrial bioenergetics and transcriptional profiles during embryogenesis in zebrafish: Implication of electron transport chain activity and developmental defects. J. Hazard. Mater. 2021, 411, 125153. [CrossRef]

41. Davis, J.A.; Gift, J.S.; Zhao, Q.J. Introduction to benchmark dose methods and US EPA's benchmark dose software (BMDS) version 2.1.1. Toxicol. Appl. Pharmacol. 2011, 254, 181-191. [CrossRef] [PubMed]

42. Chou, T.C. Preclinical versus clinical drug combination studies. Leuk. Lymphoma 2008, 49, 2059-2080. [CrossRef] [PubMed] 